\title{
Mathematical Beliefs Held by Costa Rican Pre-Service Teachers and Teacher Educators
}

\author{
Helen Alfaro Víquez ${ }^{1,2, * \mathbb{D}}$ and Jorma Joutsenlahti ${ }^{2}$ \\ 1 Department of Mathematics Education, University of Costa Rica, 11501 San José, Costa Rica \\ 2 Faculty of Education and Culture, Tampere University, 33014 Tampere, Finland; jorma.joutsenlahti@tuni.fi \\ * Correspondence: helen.alfaroviquez@tuni.fi
}

check for

updates

Citation: Alfaro Víquez, H.; Joutsenlahti, J. Mathematical Beliefs Held by Costa Rican Pre-Service Teachers and Teacher Educators. Educ. Sci. 2021, 11, 70. https:// doi.org/10.3390/educsci11020070

Academic Editor: James Albright

Received: 31 December 2020

Accepted: 7 February 2021

Published: 12 February 2021

Publisher's Note: MDPI stays neutral with regard to jurisdictional claims in published maps and institutional affiliations.

Copyright: (c) 2021 by the authors. Licensee MDPI, Basel, Switzerland. This article is an open access article distributed under the terms and conditions of the Creative Commons Attribution (CC BY) license (https:// creativecommons.org/licenses/by/ $4.0 /)$.

\begin{abstract}
Beliefs have been conceived as a hidden variable in mathematics education. It is important to know teachers' beliefs as they can inform the way that teachers teach mathematics, make decisions in the classroom, and form opinions about the abilities of students. In Costa Rica, studies about beliefs have been conducted with in-service teachers, but there is no research on pre-service teachers and the beliefs they bring to the classroom from their teacher education programs (TEPs). This research aims to describe the beliefs held by 76 pre-service teachers and 19 teacher educators from four Costa Rican public universities, using the Teacher Education and Development Study in Mathematics (TEDS-M) questionnaire. The results suggest that both pre-service teachers and teacher educators believe in a constructivist orientation focused on the learner. Both groups support the view of mathematics as a process of inquiry and active learning and agree that mathematical skills are not fixed or associated with gender or culture. In the literature, the beliefs manifested by the participants are associated with positive results regarding student outcomes and teaching practices. Therefore, policymakers should be concerned with providing environments that allow and encourage teachers to continue with these belief orientations when they start teaching.
\end{abstract}

Keywords: mathematics nature beliefs; mathematics teaching beliefs; mathematical abilities beliefs; pre-service teachers; teacher educators; TEDS-M

\section{Introduction}

The mathematical performance of Costa Rican high school students has been low in national and international tests, resulting in efforts to improve mathematics teaching and learning in the country. The ministry of public education introduced a new school curriculum in 2012, with a problem-solving approach that supports a constructivist national education policy. With this, it is expected that students have a more active and independent role in the process of learning [1]. However, the study "The State of Education" [2] shows that the curriculum has not been implemented correctly and that traditional teaching practices remain dominant, involving the transmission of knowledge from teachers to learners and a teacher-centered classroom. As one of the main reasons for this issue, the study highlights the gaps in the initial training of in-service teachers that have not been remedied with the offer of professional development. In this sense, it suggests that universities should revise their teacher education programs (TEPs) and the ministry of education, as a hiring entity, should define a national framework of qualifications for the education major. These reviews should take into account, in addition to the mathematical and pedagogical contents of the TEPs, the beliefs that teachers have about mathematics, including the teaching and learning of mathematics, since both elements influence the teaching processes.

Over time, researchers in the field of teacher education have begun to consider the study of teachers' beliefs as essential because the way that teachers conceive the world can influence their instructional practice [3-6]. Beliefs about mathematics and the teaching and learning of mathematics might define how teachers interact with students in the classroom 
and how they perceive and develop students' skills $[4,7,8]$. Furthermore, the way that teachers approach the content, the methodological choices they make, and the assessment practices they use may also be affected by their beliefs [8-10]. In other words, the assumption is that "teachers' beliefs influence how they interact with students in the classroom, thus affecting the quality of their instruction and, in turn, students' learning outcomes" [7] (p. 254).

Studies have been carried out to investigate the relationships between teachers' belief orientations and student performance [7,11,12], and the coherence between these orientations and teaching practice $[5,6,8,13,14]$. The results have shown a positive relationship between teachers who have constructivist points of view and the performance of students, for example, in solving verbal problems [12], and a negative relationship between teachers with transmission beliefs and student performance [7]. According to Voss and colleagues [7], when teachers have a constructivist orientation, they offer more opportunities for the cognitive activation of their students; therefore, pupils experience gains in achievement. However, some studies have shown that teachers' beliefs are not always consistent with their instructional practices $[8,14]$. For example, Raymond's study points out the phenomenon of new teachers holding constructivist teaching beliefs but engaging in transmission teaching in practice [15]. This pattern described by Raymond is evidenced in the studies developed in Costa Rica with in-service teachers and their students. The teachers' responses to the questionnaires are inclined towards constructivist views of mathematics, in which students are expected to be active participants. Nevertheless, students express that teachers are traditional in their teaching methodologies [16,17].

Although many of these studies have been developed with in-service teachers, including the ones in Costa Rica [16,17], it is clear that studying the beliefs of pre-service teachers is of the utmost importance as their beliefs can define their future approaches in practice [9]. Studying the beliefs of mathematics teachers before they start teaching allows us to know their vision before they are "consumed by the system," a phenomenon that many in-service Costa Rican teachers experience in the course of their teaching practice. Pre-service teachers' beliefs may be influenced by their previous experiences in school, by the social context in which they are immersed, and by the teaching they experienced in their TEPs [15]. Teacher educators play a crucial role in pre-service teachers' training as they are the ones who "design and develop the structure and contents of teacher preparation, and also are those who directly execute instruction to future teachers" [18] (p. 256). In this sense, the beliefs of teacher educators manifest in the university courses can influence pre-service mathematics teachers' beliefs and practices. Therefore, knowing teacher educators' beliefs is important to attain a more informed overview of the factors that shape future teachers' beliefs.

Considering the above, this study aims to describe the beliefs expressed by the preservice teachers and teacher educators who are part of Costa Rican TEPs, to offer policymakers and university authorities inputs that can illuminate decision-making in modifying or updating the TEPs. To achieve this aim, we used the Teacher Education and Development Study in Mathematics (TEDS-M) questionnaire. The TEDS-M study, conducted with data from 17 countries, includes research on the beliefs of pre-service teachers and those of their educators about the nature of mathematics, teaching and learning, and the abilities of students [10].

\section{Theoretical Framework}

\subsection{Understanding the Concept of Belief}

Teachers' beliefs are considered an element of cognition that affects teaching and has been used to explain the nature of teachers' instruction [5]. Defining this concept is not an easy task; teachers' beliefs have been considered "a 'messy construct' with different interpretations and meanings" [5] (p. 365) that is interchangeable with terms such as conceptions, opinions, attitudes, and knowledge. Many researchers, including Pajares in his seminal work, have attempted to provide a clear definition of beliefs and particularly to differentiate between beliefs and knowledge $[4,19]$. A characteristic that makes the 
difference between the concepts evident is the existential feature of beliefs that defines them as personal truths (subjective), while knowledge is considered an objective social construct shared by the general public $[6,20]$. As stated before, there is no consensus on the definition of beliefs. Some attempts to define the concept have used approaches from the fields of psychology and cognition. Therefore, some authors define beliefs as subjective mental constructs to which a person gives value and which are relatively stable [21,22]. Other explanations consider beliefs to be psychologically held understandings or premises about the world that the subject assumes true [7,23]; these understandings are shaped by cultural influences [9]. In the field of mathematics education, Schoenfeld considers beliefs "as an individual's understandings and feelings that shape the ways that the individual conceptualizes and engages in mathematical behavior" [24] (p. 358). With these notions of beliefs in mind, it makes sense that teachers' beliefs shape their practice and inform their decision-making on the knowledge that is important to teach, teaching methods, and the goals to reach in the class $[4,5]$. Some authors even claim that beliefs can be seen as the bridge between teacher knowledge and actual teaching $[8,9,25,26]$.

In the field of mathematics education, the original rationale for investigating teachers' beliefs comes from the idea that beliefs can explain how mathematics is taught and learned [21]. In other words, studying the beliefs of mathematics teachers can provide "insight into the way teachers understand and carry out their job" [27] (p. 43). Beliefs in mathematics education have been categorized in different ways [28,29]. Specifically, as mentioned by Voss et al. [7], teachers' beliefs can be grouped into three levels of belief systems. One level includes the beliefs that teachers have about themselves, their role as teachers, and their teaching abilities. Beliefs about the immediate context of teaching and learning are part of another level, which includes beliefs about the teaching and learning of mathematics and of knowledge of mathematics. Finally, there is a level that includes beliefs about the policies of educational systems and the social context. The literature on mathematics education focuses on teachers' beliefs regarding the nature of mathematics and teaching and learning [5]. These elements, together with the teachers' perceptions of the students' mathematical abilities, are those contemplated in the TEDS-M study's structure of beliefs [10], which we used in this study.

\subsection{Beliefs Areas of Mathematics Teachers}

The TEDS-M study considered three areas of teachers' beliefs, as presented in Figure 1. These are (a) beliefs about the nature of mathematics; (b) beliefs about teaching and learning; and (c) beliefs about students' mathematical abilities [10]. These categories, in turn, are divided into Likert scales.

\section{MATHEMATICS TEACHER' BELIEFS}

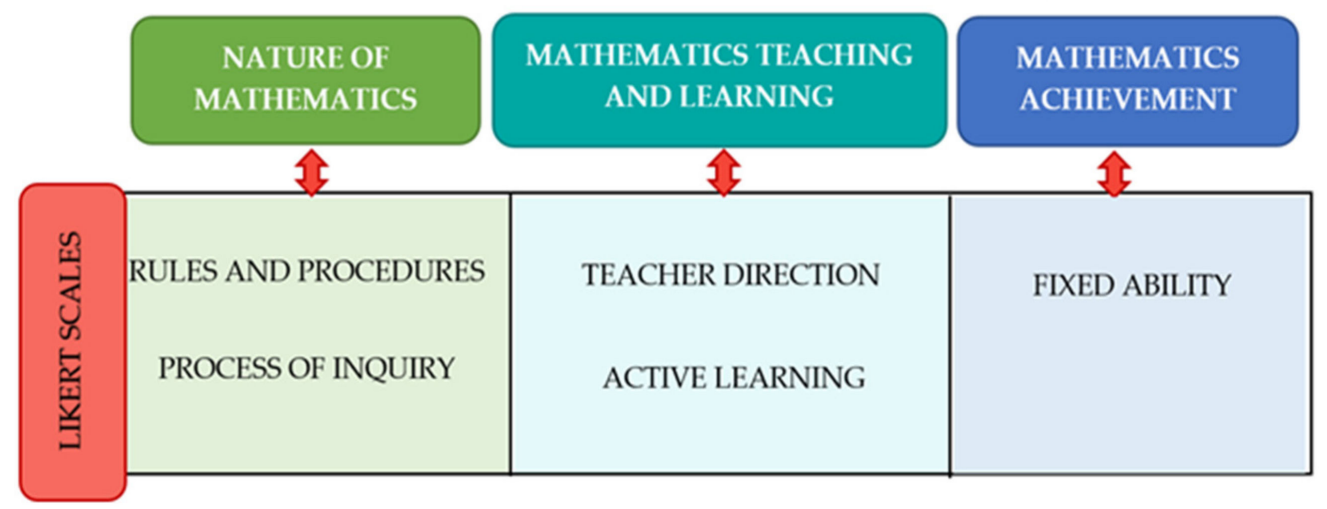

Figure 1. Teacher Education and Development Study in Mathematics (TEDS -M) study structure of beliefs.

The first area considers beliefs about the nature of mathematics that are derived from the epistemological study of beliefs; that is, it includes the nature of knowledge and the 
nature of knowledge. Blömeke and Kaiser [30] mention different ways in which these beliefs have been classified. One of the approaches presents three fundamental views: instrumentalist, Platonist, and problem-solving. These three views coincide, respectively, with the traditionalist, formalist, and constructivist conceptions of another of the categorizations. However, as they state, the TEDS-M study utilizes the approach developed by Grigutsch and colleagues [31], which has two fundamental beliefs regarding the nature of mathematics: the static view and the dynamic view. Considering mathematics as a static system means seeing it as an unalterable unified entity [9], as a set of rules and procedures [30]. In this regard, the framework of the TEDS-M study defined the scale of rules and procedures for investigating pre-service teachers' and teacher educators' beliefs. Agreeing on this scale will mean to conceive mathematics as a set of rules that need to be memorized and applied in the solution procedures. In contrast, conceptualizing mathematics as a dynamic process implies conceiving the subject as something that is in a constant process of change and revision, which also requires the activation of creativity to generate new knowledge or solution paths [9]. The scale designated for this view is named process of inquiry.

In the area of beliefs about teaching and learning, the literature has suggested different approaches [7]. The one that informs the TEDS-M framework developed by Peterson and colleagues. From this approach, we can extract two major categories: transmission and constructivist [11]. In the transmission view, the teacher acquires the role of possessor and transmitter of information and knowledge, while the student has the passive role of a receiver that must obey the teacher's instructions [30]. The scale of teacher direction can be associated with this category. On the other hand, the constructivist category gives the student greater responsibility in the process of knowledge and meaning construction. In this vision, the teacher must mediate in the creation of environments that promote the active participation and engagement of students in learning [7,30]. The scale of active learning is related to this category.

The third area of beliefs considered in the TEDS-M study concerns teachers' beliefs about students' abilities to learn mathematics, including topics about whether gender and culture influence the learning of mathematics. In this sense, the study only includes a scale called fixed ability, which studies whether teachers conceive the ability to learn mathematics as something stable that cannot be changed, despite efforts to improve, or as a body of skills that can be built through the learning process [18].

The general results of the TEDS-M study show that the most common pattern across countries was to endorse strongly the statements viewing mathematics as a process of inquiry that requires active student learning. The views of mathematics as a set of rules and procedures that requires the direction of a teacher to learn received less support. The view of mathematics as a fixed ability was strongly rejected by most of the participant countries [10].

\subsection{Teacher Profiles According to the Beliefs Held}

The previous description of the main categories in each of the areas of beliefs can make them seem opposite and incompatible; it could be assumed that a teacher has the beliefs of one category or another. However, as demonstrated by Voss et al. [7], "constructivist and transmissive beliefs are not two ends of a one-dimensional continuum and are not mutually exclusive categories ... they are two distinct, negatively correlated dimensions" (p. 257). Furthermore, considering belief systems as psychological constructs, it is important to bear in mind that they do not have a logical order; thus, in some cases, they may be contradictory or inconsistent [6]. Therefore, a teacher can see mathematics as a set of rules and procedures and also think of it as a process of inquiry. From this perspective, Wang and Hsieh [18] used the TEDS-M results to identify teacher profiles according to their beliefs in each area. In this way, they labeled as comprehensive the class of teachers who supported the idea of mathematics as a set of rules and procedures and, at the same time, considered mathematics to be a process of inquiry. The class of teachers who only 
supported the latter opinion was called the inquiry preferred profile. The teachers who endorsed both the belief that the study of mathematics requires active learning and the idea that teacher direction is still needed were categorized in the comprehensive class for the teaching and learning area. Those who supported the idea of active learning and not that of teacher direction were classified as active learning preferred. Finally, for the area of mathematical abilities, teachers who conceived mathematical abilities as fixed, as resulting from natural talent, and as differing according to gender or culture were placed in the entity-view-endorsed class. The class for the teachers disagreeing with this view was named incremental-view-endorsed.

\subsection{Research Questions}

As has been stated, studying the beliefs of pre-service teachers is useful to get an idea of what their teaching practice might be like, for example, regarding instruction methods or how they address the learning needs of students. Along the same lines, studying the beliefs of teacher educators can illuminate the reasons why pre-service teachers formed their beliefs in a certain way. Therefore, studies on the subject are important to update and improve TEPs. However, in Costa Rica, the issue of the mathematical beliefs of these groups has not yet been investigated. We aim to collect information about both groups of interest and investigate what they believe about the nature of mathematics, mathematics teaching and learning, and mathematical abilities. In addition, informed by the literature, we consider it important to study how the beliefs held by the participants relate to other factors, such as academic background or TEPs. Hence, we pose the following research questions:

1. What are the beliefs of Costa Rican pre-service teachers and teacher educators about the nature of mathematics, mathematics teaching and learning, and mathematical abilities?

2. What factors are related to the beliefs of Costa Rican pre-service teachers?

(a) How are school performance and the beliefs of pre-service teachers related?

(b) How are TEPs and the beliefs of pre-service teachers related?

(c) How are the performance on the TEDS-M test and the beliefs of pre-service teachers related?

3. What factors are related to the beliefs of Costa Rican teacher educators?

(a) How are academic background and the beliefs of teacher educators related?

(b) How are years of experience and the beliefs of teacher educators related?

(c) How are special preparation for teaching and the beliefs of teacher educators related?

Answering these research questions will meet our goal of providing a description of the beliefs of the Costa Rican pre-service teachers and teacher educators and factors that can influence them.

\section{Materials and Methods}

\subsection{Mathematics Teacher Education in Costa Rica}

To become a secondary school mathematics teacher in Costa Rica, one can major in mathematics teaching at a public or private university. With a degree in this major, it is possible to teach from grade 7 to 11 in high school, and sometimes, when needed, the basic mathematics courses at universities. Currently, there are eight universities that offer the specialty, of which four public institutions agreed to participate in this research.

In the TEPs of these public institutions, four years are necessary to obtain a bachelor's certificate and one more year for a licentiate degree. The TEPs involve tertiary mathematics, mathematics education, and general pedagogy courses. The courses are not taken in separate blocks but are distributed in such a way that students attend courses in each area every semester. The area that receives the most emphasis in the four programs in tertiary mathematics, while general education pedagogy receives the least. The general distribution 
of the courses in the four TEPs is similar in terms of the proportions dedicated to each area, $45 \%$ to tertiary mathematics courses, $37 \%$ to mathematics pedagogy and $18 \%$ to general pedagogy. However, there is variability between the number of topics covered by each university. For example, Universities $C$ and D offer more mathematics education pedagogy topics than the rest, but the former offers more courses in tertiary mathematics than D [32]. In addition to these variations in their academic offerings, TEPs have differences in terms of their focus and resources. The program at Universities A and B contains the same courses; however, as they are developed in different locations, University A serves more students and has more teacher educators. On the other hand, University D has a program focused on teaching mathematics using technological environments, which is also the only one in the area of education at that institution. The other three universities have courses in their curriculum that they share with students from other education majors.

The training of mathematics teachers who participate in this study is carried out mainly by mathematicians and education professionals. Lately, teacher educators specializing in mathematics education have also joined. Nevertheless, very few of them have special training for preparing future mathematics teachers.

\subsection{Participants}

For the selection of the sample, a convenience sampling was used; that is, the selection criterion was based on the disposition of the institutions to collaborate, taking into account that the eight universities that train mathematics teachers were contacted, and only four participated. Likewise, the participants, both teacher trainers and teachers in training are the ones who agreed to fill out the survey. Their sample consists of two groups of participants: the pre-service teachers and the teacher educators. The first group is composed of 76 pre-service mathematics teachers from four public universities in Costa Rica who were in the last year of their TEPs. This sample represents the total of students in these conditions from these institutions. In this sample $43(\mathrm{~N}=76)$ students are male and 33 are female, with ages ranging from 20 years to 33 years $(\mathrm{M}=23.8, \mathrm{SD}=2.9)$. Nineteen teacher educators from the four institutions answered the questionnaire that was sent to them by mail, nine of them are women, and 10 are men. They have between two and 20 years of experience in preparing mathematics teachers $(M=9.3, S D=5.2)$. There are six interim professors (who are hired for one or more semesters) and 13 tenured professors (with permanent contracts). Regarding the academic level, there are six professors who hold a PhD: three in mathematics, two in education, and one in mathematics education. There are 10 instructors holding a master's degree: one in mathematics, four in education, and five in mathematics education. Finally, 13 have a licentiate degree: one in education and 12 in mathematics education. The distribution of both groups of participants by the university is shown in Table 1. The sample from University B is smaller than the others since it is a campus that serves less population. Therefore, when the results are presented by the university, they must be interpreted with caution.

Table 1. Participant distribution by university

\begin{tabular}{ccc}
\hline University & Pre-Service Teachers & Teacher Educators \\
\hline A & 23 & 7 \\
B & 8 & 3 \\
C & 19 & 5 \\
D & 26 & 4 \\
Total & 76 & 19 \\
\hline
\end{tabular}

Note: the letters A, B, C, and D are used as pseudonyms for universities.

\subsection{Data Collection}

For data collection, we used the TEDS-M questionnaire of the International Association for the Evaluation of Educational Achievement (IEA). With the permission of the IEA, the questionnaire was translated into Spanish by the first author. In the same way, 
the necessary adjustments were made so that the questionnaire was contextualized to the reality of Costa Rica. Both the translation and the contextualization were reviewed by three Costa Rican professors of mathematics education who were outsiders to the project. The full questionnaire for pre-service teachers has four parts: background information, opportunities to learn, a test to evaluate mathematical content knowledge and mathematical pedagogical content knowledge, and beliefs. The second and third parts have been analyzed in a previous study [32]; in this study, we focus on the beliefs part. In this regard, both groups of respondents had the same questionnaire. The pre-service teachers answered the questionnaire on paper, while the teacher educators completed it online for their convenience. Participation in this study was voluntary, and both groups were informed that their responses would remain anonymous.

The beliefs are investigated using Likert scales, and the questionnaire has three sections: beliefs about the nature of mathematics, beliefs about learning mathematics, and beliefs about mathematics achievement. The first section is divided into two scales, one with a statement that assesses the belief that math is a set of rules and procedures and another one that considers math as a process of inquiry. For the section on beliefs about learning mathematics, there is a scale considering whether mathematics should be learned by following the teacher's direction and another in which learning requires active involvement. The last section has one scale focused on the view of mathematics as a fixed ability. There were six response options ranging from "strongly disagree" to "strongly agree." The reliability of the Likert scales was calculated in the TEDS-M study using Cronbach's alpha coefficient, which ranged between 0.86 and 0.93 , and the items have been examined by expert panels [33].

The background questions were different for pre-service teachers and teacher educators. Pre-service teachers were asked about the grades they usually received in high school, ranging from "generally below average" to "always at the top" of their year. The teacher educators were asked about their academic background in mathematics, their mathematics education, whether they received preparation for training pre-service teachers, and their teaching experience in high school and university.

\subsection{Analysis}

The data collected in the questionnaire were quantitative. Once all the questionnaires had been gathered, the data of the Likert scales from both groups were coded and cleaned. The original number of pre-service teachers was 80 . However, four of them had high percentages of missing data, so a list-wise deletion was applied, leaving a final sample of 76. In the case of the teacher educators, for the few cases of missing data presented, a median imputation was applied. For the analysis, we used quantitative methods. First, we used descriptive statistics to show the level of agreement of the participants regarding the Likert scales. Here we applied two measures: the percentage of endorsement of the scale from each group and the average level of agreement to each statement per group. For computing the percentage of endorsement of each scale, we followed the TEDS-M methodology [10]. Hence, we considered that responses 1 to 4 ("strongly disagree" to "slightly agree") do not support the statement and responses 5 to 6 ("agree" and "strongly agree") endorse it. The proportion of answers endorsing the scales represents the groups' support for the beliefs. The average level of agreement corresponds to the mean of the respondents' answers to each statement. Second, we performed nonparametric tests to analyze correlations and data distributions. We chose nonparametric tests due to the size of the sample.

\section{Results}

\subsection{Nature of Mathematics}

The area of the nature of mathematics has two belief scales: mathematics as a set of rules and procedures and mathematics as a process of inquiry.

Regarding the first scale, the results presented in Figure 2 show that only $35.6 \%$ $(n=76)$ of the pre-service teachers endorse this view, which means that the majority 
do not see mathematics as only rules to memorize and procedures to follow. When analyzing the data by the university, University B shows $62.5 \%$ agreement and University D $42.3 \%$. This indicates variations among the participants from the different TEPs in this regard; however, the chi-squared test of independence showed that there was no significant association between the TEP of belonging and the endorsement to this belief, $X^{2}(3, N=76)=6.4, p>0.05$. The teacher educators also disagree with this view, with only $26.4 \%(n=19)$ of them supporting it. In the same way, the proportion of teacher educators supporting the rules and procedures beliefs is not associated with the university where they teach, $X^{2}(3, N=19)=2.4, p>0.05$. Here, it is interesting to note that none of the teacher educators from University B endorsed this view, despite the fact that the majority of their students did. This may be because the students forged those beliefs from experiences prior to their TEP, and the instruction during the program did not modify these beliefs. It could also mean that teacher educators differ in their espoused and enacted beliefs. The average level of agreement of pre-service teachers is $4.05(\mathrm{SE}=0.1)$, and that of teacher educators is $3.56(\mathrm{SE}=0.26)$.

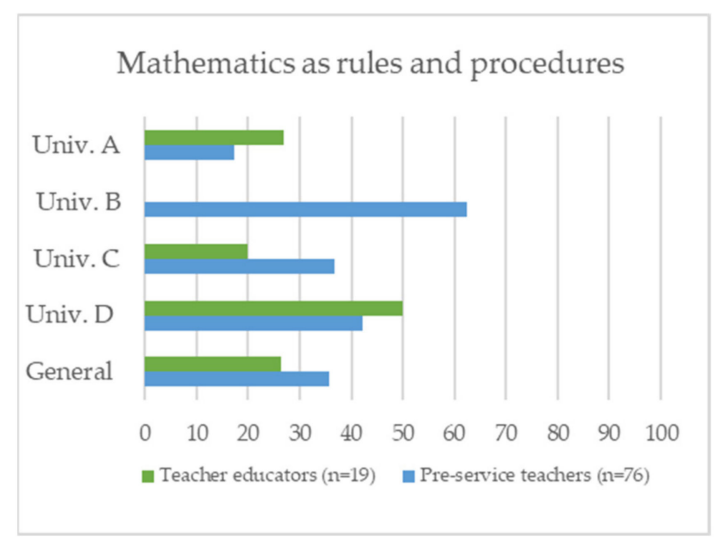

Figure 2. Percentage of endorsement of the view of mathematics as a set of rules and procedures.

The second scale studies the beliefs of the participants regarding the view of mathematics as a process of inquiry. On this topic, the endorsement was almost unanimous in both groups: $92.2 \%(n=76)$ of the pre-service teachers and $89.5 \%(n=19)$ of the teacher educators. The average levels of agreement are $5.23(\mathrm{SE}=0.08)$ and $5.39(\mathrm{SE}=0.15)$, respectively. In Universities A and C, the support was slightly higher from the students than from the educators, as observed in Figure 3. Nevertheless, as shown by the chi-squared test of independence, the view of mathematics as a process of creativity and discovery is shared in all the TEPs, being $X^{2}(3, N=76)=1.4, p>0.05$ the results for pre-service teachers and $X^{2}(3, N=19)=1.4, p>0.05$ the ones for teacher educators.

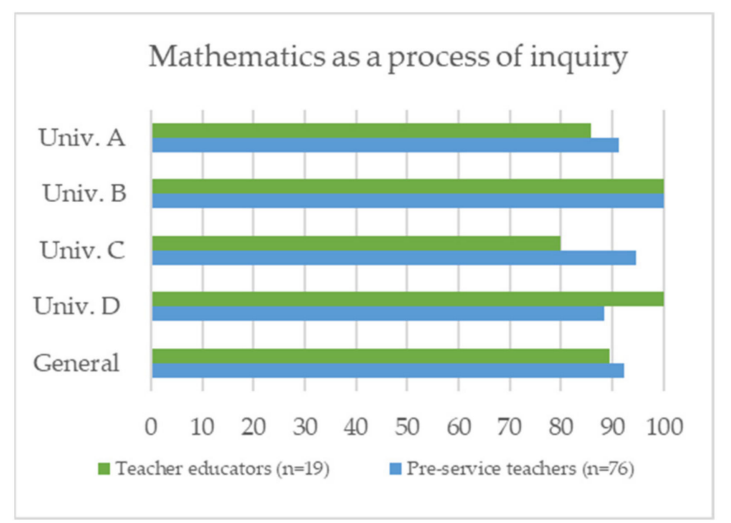

Figure 3. Percentage of endorsement of the view of mathematics as a process of inquiry. 
Following Wang and Hsieh [18], the profile of both groups of participants can be defined as inquiry preferred, where the view of mathematics as a set of rules is not endorsed, but the one that considers mathematics as a process of inquiry and creativity is. Yet, if we analyze the groups by the university, the pre-service teachers from University B follow a comprehensive profile because the majority of them support both views-mathematics as rules and procedures, and as a process of inquiry.

In Figure 4, it is possible to observe the participants' responses for each Likert statement regarding the nature of mathematics. Considering four as the neutral point, we can see from the means that the respondents agreed with three statements of the rules and procedures scale: 1B, 1D, and 1E. Hence, while both groups of participants disagree with limiting the meaning of mathematics to a set of rules that must be learned, remembered, and followed to solve problems, they recognize that definitions, formulas, and strategies for solving problems are necessary to do mathematics. On this scale, the level of agreement of the teacher educators was lower than or equal to that of the pre-service teachers for all the statements, but the differences are not large.

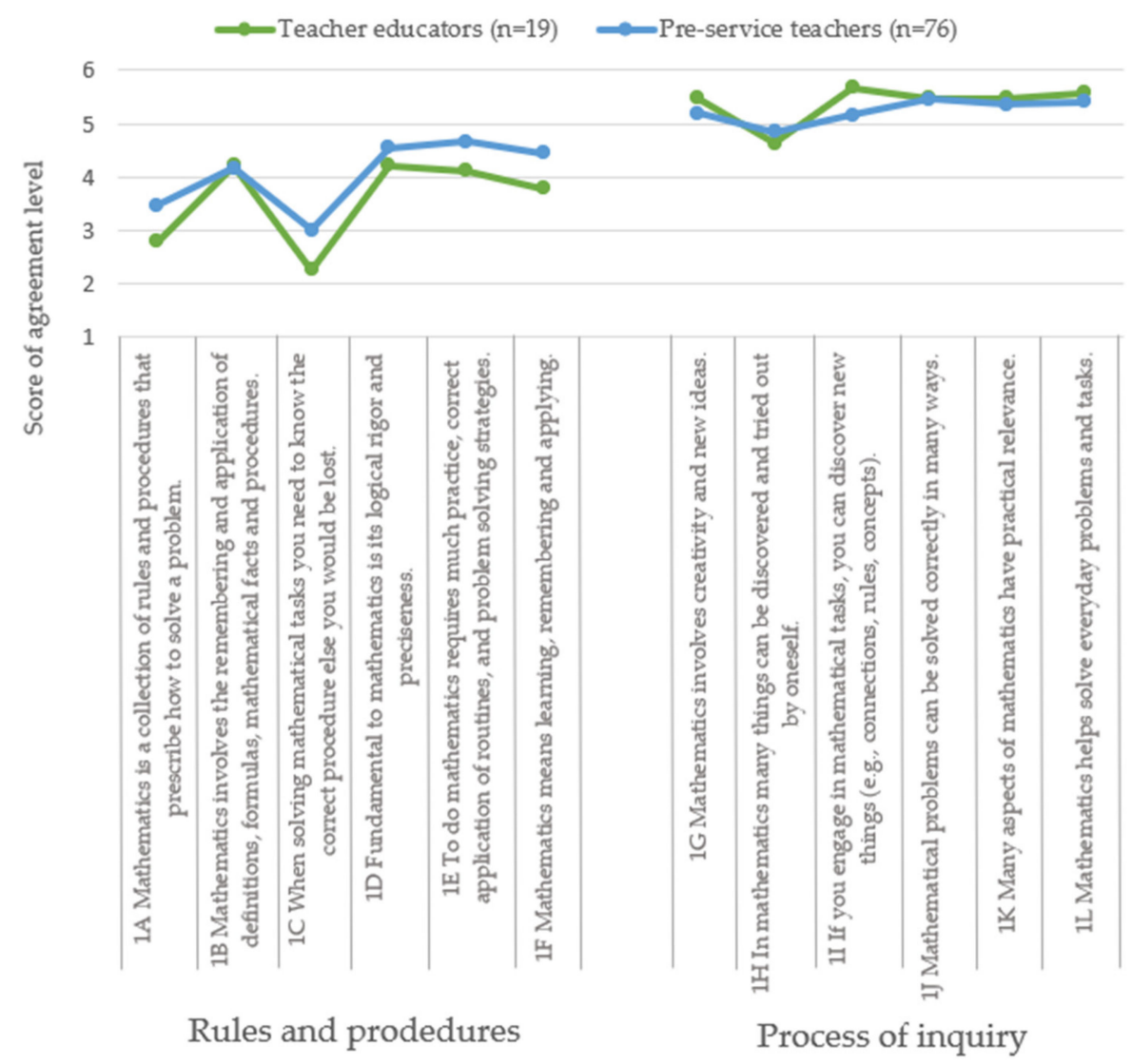

Figure 4. Average level of agreement of the participants on the scales of the nature of mathematics. Note: statements are taken from TEDS-M questionnaire.

Regarding the process of inquiry view, as mentioned before, it is strongly supported. The statement that shows the lowest mean (4.63 for teacher educators and 4.84 for preservice teachers) is $1 \mathrm{H}$, which states that "In mathematics many things can be discovered and tried out by oneself." This suggests that there is still doubt about doing mathematics without a guide. The level of agreement of both groups shows a similar pattern; however, teacher educators seem to be a little more skeptical about discovering things in mathematics than pre-service teachers. 


\subsection{Teaching and Learning Mathematics}

When studying beliefs, it is also important to include the thoughts of the participants about how mathematics is taught and learned. In this sense, two scales were studied, one which considers that the teaching and learning of mathematics need strong direction from the teacher and the other in which more importance is given to the active learning of students. The participants' position in this category is strong. Neither group agreed with the teacher direction view ( $0 \%$ endorsement). The average level of agreement of teacher educators is $1.9(\mathrm{SE}=0.17)$, and that of pre-service teachers is $2.1(\mathrm{SE}=0.75)$. This reflects a consensus on the idea that in mathematics teaching and learning, the teacher should not be the protagonist. Both groups endorse the idea that the approach to learning mathematics should be an active one. The support for this view is solid, with $94.7 \%$ of the teacher educators $(\mathrm{n}=19)$ agreeing, with an average level of agreement of $5.52(\mathrm{SE}=0.12)$, and $96.1 \%$ of the pre-service teachers $(\mathrm{n}=76)$, with an average of $5.4(\mathrm{SE}=0.56)$ for the level of agreement. Overall, the results show a homogeneous agreement regarding the beliefs about teaching and learning mathematics from both groups, without significant differences between the belief endorsement and the university neither by the pre-service teachers, $X^{2}(3, N=76)=6.0, p>0.05$, nor by teacher educators, $X^{2}(3, N=19)=3.9, p>0.05$. It seems that participants from all TEPs follow an active-learning-preferred profile [18]. This means that both teacher educators and pre-service teachers agree that students should be actively engaged in the learning process rather than being mere recipients of teacher instructions. Thus, they agree that students should engage in activities that allow them to discover and test their own strategies for solving exercises, understand why strategies work, and decide why some are better than others.

The level of agreement with each statement of the teaching and learning mathematics scale is shown in Figure 5. The beliefs of both groups follow a similar pattern. In the teacher direction scale, the statement that had more support (2.58 from teacher educators and 2.75 from pre-service teachers) was $2 \mathrm{E}$, which states that pupils learn best by following teachers' explanations. This result is consistent with the one regarding the process of inquiry scale suggesting the need for a guide, instead of the idea of students discovering by themselves. In the scale of active learning, the statement that had slightly less support (5.37 from teacher educators and 4.93 from pre-service teachers) in both groups was $2 \mathrm{M}-$ “Teachers should encourage pupils to find their own solutions to mathematical problems even if they are inefficient." The use of the word inefficient likely influenced the participants' decision. Both groups of respondents totally disagreed with statement $2 \mathrm{C}$, which states that understanding the problem and its solutions is not as important as getting the correct answer. This result is consistent with the inquiry's preferred view on the nature of mathematics and the active learning position.

\subsection{Mathematical Abilities}

In this category, we analyze whether the participants perceive mathematical ability as a fixed ability that depends on natural talent and has categorical differences depending on gender or culture, or whether it is something that can grow and change. The computed scales for this category show that there is no support for the former perspective in either group: $0 \%$ of the participants agree. The average level of agreement of both groups is low, considering the 1-6 scale; for pre-service teachers, it is $2.4(\mathrm{SE}=0.08)$ and for teacher educators $2.1(\mathrm{SD}=0.16)$. In Wang and Hsieh's terms [18], this corresponds to an incremental-view-endorsed. Although the general disagreement with this vision is strong, the participants were less firm in disapproving of the statements $3 \mathrm{~F}$ ("Mathematical ability is something that remains relatively fixed throughout a person's life"), which had a mean of 2.45 from teacher educators and 3.17 from pre-service teachers, and 3G ("Some people are good at mathematics and some aren' $t^{\prime \prime}$ ), which had an average level of agreement of 3.53 in both groups. In this way, the participants show that they are totally against the idea that mathematical skills are linked to cultural or gender aspects, or even that they are due 
solely to natural talent. They only slightly disagreed that math skills can be improved over time and that there are people who are good at math and others who are not.

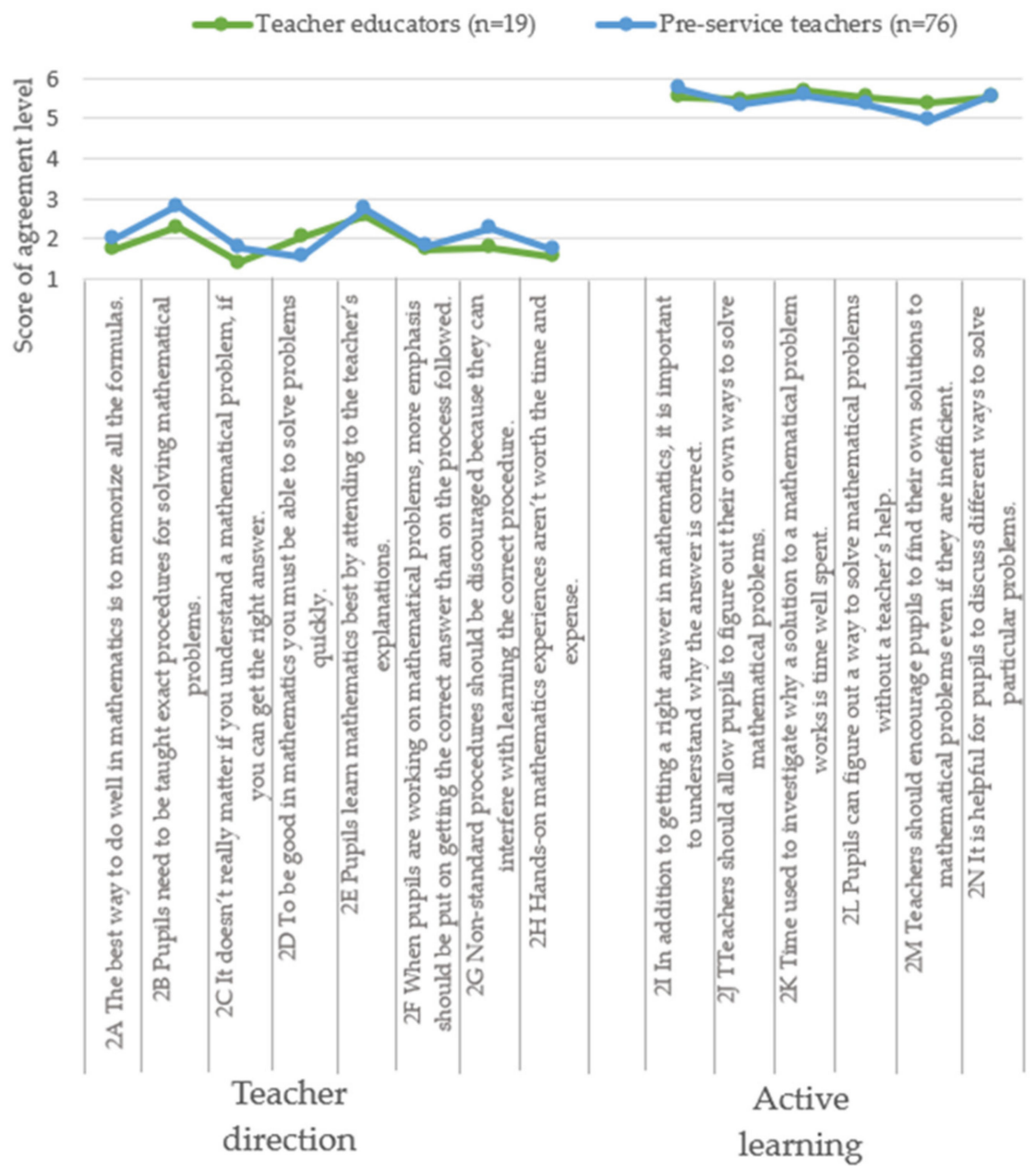

Figure 5. Average level of agreement of the participants on the scales of mathematics teaching and learning. Note: statements are taken from TEDS-M questionnaire.

In Figure 6, it is possible to observe that the level of agreement with the statements of this scale is very similar in both groups of participants. That is, teacher educators and pre-service teachers hold similar beliefs about mathematical abilities.

4.4. Relations between Pre-Service Teachers' Beliefs and Their Background and Performance in the Mathematical Knowledge Test

According to the literature, beliefs about mathematics are strongly influenced and formed by participants' experiences [34], and in the case of pre-service teachers, TEPs also have a moderate influence [15]. Therefore, we studied whether the beliefs of pre-service mathematics teachers are related to variables such as their TEPs and their high school grades. In addition, we studied whether there is a relationship between their beliefs in the different areas and their performance in the TEDS-M test about their mathematical knowledge (presented in a previous study [32]).

Regarding the association between TEPs and the participants' beliefs, we considered the variable distributions. The Kruskal-Wallis $\mathrm{H}$ test found that the distribution of the five beliefs scales was the same among the four universities, suggesting that the pre-service teachers' beliefs are homogeneous despite the differences between TEPs and the teacher educators in each university. 


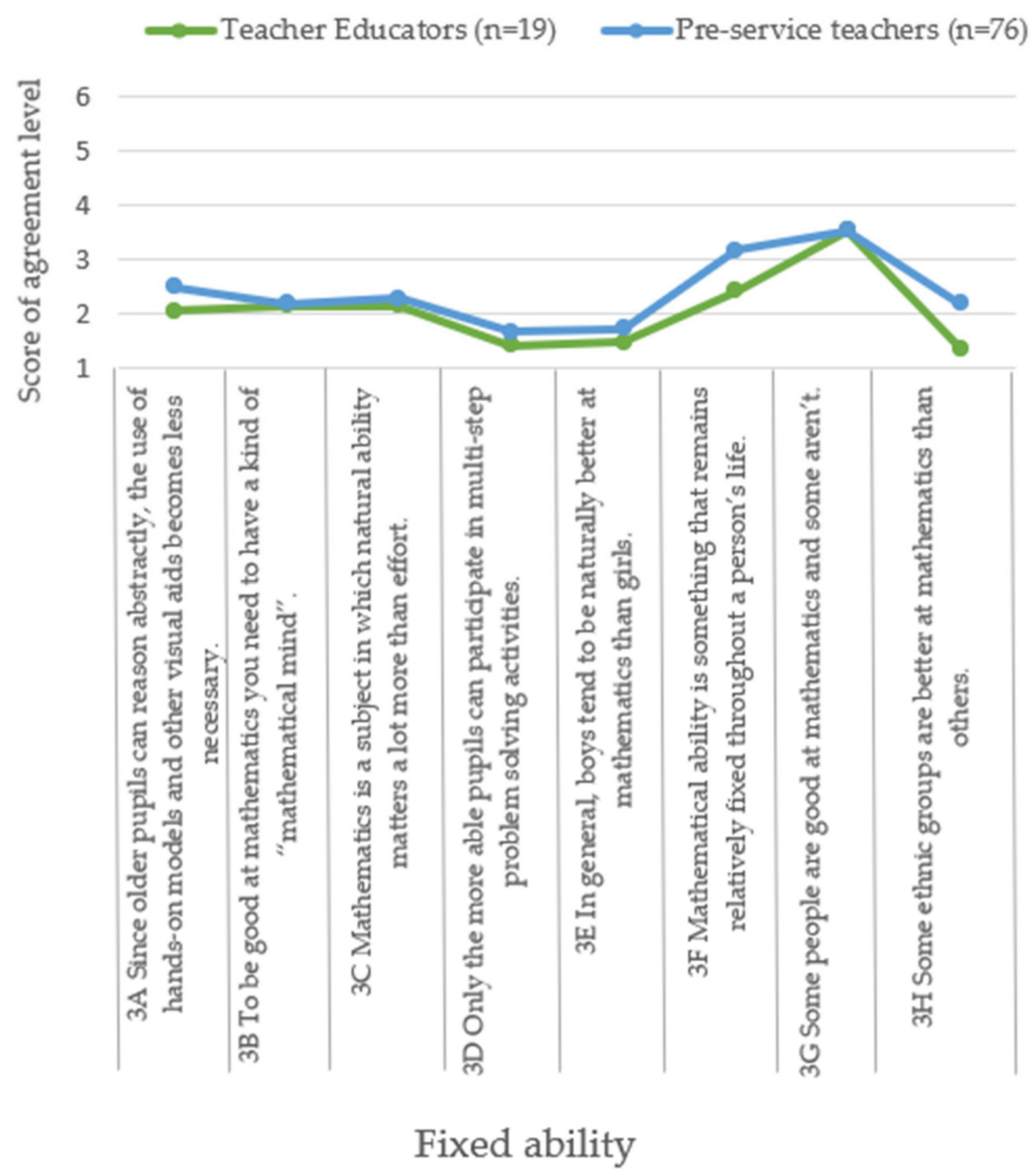

Figure 6. Average level of agreement of the participants on the scales of mathematical abilities. Note: statements are taken from TEDS-M questionnaire.

The analysis of correlations between the belief areas and the pre-service teachers' high school grades showed that there were no significant correlations between the pre-service teachers' high school grades and their beliefs about the nature of mathematics or teaching and learning. The only area that showed a correlation, according to Spearman's analysis of correlation, was the belief that math is a fixed ability. There was a small negative correlation $\left(\mathrm{r}_{\mathrm{s}}=0.27, \mathrm{n}=76, p \leq 0.05\right)$ between those two variables. This suggests that respondents who had higher grades in high school gave less support to the idea that mathematical abilities do not change and are just for some people. With these results, and considering their high school grades as a variable of their school experience, it is not possible to know much about the relationship between the participants' experience and the beliefs they have about mathematics. Still, we can mention the fact that having a good academic performance in high school led the pre-service teachers to see mathematical ability as something reachable for all kinds of learners.

Finally, we did Spearman's analysis to explore the relationships between the belief scales and the participants' mathematical knowledge. When considering the whole sample, we found correlations between only two variables - the test scores and the belief in mathematics as rules and procedures-which had a small negative correlation $\left(r_{s}=-0.24\right.$, $\mathrm{n}=76, p \leq 0.05$ ). This means that the participants with better performance in the test show less agreement with that view of mathematics. Mathematical knowledge and the other belief scales were not associated with our data. However, when performing analyses with the pre-service teachers by a university, we observed other relations. For instance, there was a medium positive correlation $\left(\mathrm{r}_{\mathrm{s}}=0.46, \mathrm{n}=23, p \leq 0.05\right)$ between the mathematical knowledge of the participants from University A and the belief in math as a fixed ability. The same happened with participants from University B, but the association, in this case, 
was large $\left(\mathrm{r}_{\mathrm{s}}=-0.71, \mathrm{n}=8, p \leq 0.05\right)$. Here, the participants with higher scores in the test tend to have a higher level of agreement with this belief; nevertheless, they reject the idea of math as a fixed ability, with a mean level of agreement of 2.4 on a scale from 1 to 6 . The mathematical knowledge evidenced in the test of the participants of University B was negatively related to the beliefs scale of rules and procedures $\left(\mathrm{r}_{\mathrm{s}}=-0.84, \mathrm{n}=8, p \leq 0.05\right)$, which coincides with the general result. Finally, the data from the participants of University C showed a medium positive association $\left(\mathrm{r}_{\mathrm{s}}=0.41, \mathrm{n}=19, p \leq 0.05\right)$ between mathematical knowledge and the scale of the process of inquiry. That is, the better participants performed in the test of mathematical knowledge, the more they agreed with considering mathematics as a process of inquiry. It is important to highlight that these analyses were conducted to explore the relations suggested in the literature [10], but there is no intention to draw definite conclusions.

\subsection{Relations between Teacher Educators' Beliefs and Their Academic Background, Years of Experience, and Special Preparation for Teaching}

Considering academic background, years of teaching, and special preparation for teaching as part of the experience of teacher educators, we examined whether those factors were associated with their beliefs. For this purpose, we ran Spearman's analysis. First, we investigated whether teacher educators' academic background was related to the way they perceive the nature of mathematics, learning, and achievement. For this variable, the teacher educators were asked for their highest qualification in mathematics, mathematics education, and education. The possible degrees were bachelor's, licentiate, master's, or doctorate. The results evidenced that participants with a higher degree in mathematics education more strongly endorsed the belief that active learning is required to learn mathematics $\left(\mathrm{r}_{\mathrm{s}}=0.48, \mathrm{n}=19, p \leq 0.05\right)$. It seems that the more preparation they have in mathematics education, the clearer the need to implement that kind of teaching. The other two academic areas were not associated with any of the beliefs.

To examine the association between years of experience and areas of belief, we conducted Spearman's analysis for years of high school teaching, years of university teaching, and years of math teacher preparation. The results showed no relationships between these variables and the beliefs. In addition, we studied whether receiving special preparation for training teachers was related to the teacher educators' beliefs, and the findings did not show a significant relationship. Finally, the outcomes of the Kruskal-Wallis H test found that the distribution of the five belief scales was the same among the teacher educators from the four universities, as with the pre-service teachers. Here it is important to keep in mind that the sample of teacher educators was small $(n=19)$.

\section{Discussion}

As reported by the literature, the study of teachers' beliefs about a subject is essential to understand their practice. The beliefs that a teacher has about the nature of mathematics, for example, will influence his way of interpreting mathematical knowledge as static or dynamic, and consequently, will also inform his way of teaching [4,30]. In this study, we investigate three areas of beliefs of 76 pre-service teachers and 19 teacher educators from four universities in Costa Rica in order to provide a description of the beliefs they manifest and how they are related to other variables. In the following, we will discuss our findings in two parts; the description of participants' beliefs orientations on one hand, and the association of those beliefs with other variables, on the other.

\subsection{Descriptive Analysis of Pre-Service Teachers and Teacher Educators Beliefs}

Our first research question was about the participants' beliefs regarding the nature of mathematics, teaching and learning mathematics, and mathematical abilities. In this sense, for the area of beliefs of the nature of mathematics, the outcomes showed that both groups of participants do not support the static view of mathematics as a set of formulas, definitions, and procedures that must be memorized and applied. Instead, they agreed that mathematics is a dynamic process of search and discovery, in which it is important 
to know and study mathematical concepts, as well as to have the teacher's guidance. Thus, both Costa Rican pre-service teachers and teacher educators are classified in the inquiry-preferred profile, which is also the one manifested by pre-service teachers and teacher educators from Germany, Switzerland, Russia, and Norway. However, pre-service teachers from countries closer to Costa Rica, such as the United States and Chile, have a preference for the comprehensive profile [18].

It is also shown in the results about the teaching and learning beliefs that both groups of research subjects completely reject the transmissive view in which learning mathematics is about memorizing formulas, repeating exact procedures, and getting the correct answer. Instead, they fully support the idea that learning mathematics requires the active participation of students, related to a constructivist conception. Based on that, participants are classified in the active-learning-preferred profile, which is also more prevalent internationally. Wang and Hsieh's study [18], which used data from 15 TEDS-M countries, shows that prospective teachers from 11 countries and teacher educators from eight countries also belong to the active-learning-preferred profile.

By combining the findings on the first two belief areas, we can highlight two points. First, despite the fact that it is theoretically possible to support the ideas of both orientations [7], the beliefs of the Costa Rican participants were maintained in only one of them. Second, it can be inferred that the beliefs of pre-service teachers and teacher educators in Costa Rica manifest the characteristics of a dynamic constructivist orientation [8] and also share the common pattern of supporting views described in the TEDS-M study [10]. Finding that Costa Rican teachers in training and teacher educators manifest this orientation of beliefs adds information to the scarce knowledge on this subject in Latin American countries, where most studies on teachers' beliefs consider teachers in service.

In the Costa Rican context, the results of this study show consistency between the beliefs of the respondents and teachers in service who declared earlier that they had constructivist beliefs $[16,17]$. Previous studies about the relationship between teacher beliefs and student outcomes have shown that this belief orientation is "positively related to instructional quality and student learning outcomes" [7] (p. 264), so one would expect to observe teaching practices that encourage active student participation, resulting in Costa Rican students' better performance in mathematics. However, the classroom observations described in the study "The State of Education" reveal traditional teaching methods [2], and high school students even categorize their mathematics classes as focused on learning algorithms [17]. Therefore, in-service teachers are implementing teaching strategies that are negatively related to positive outcomes [7]. These facts suggest the existence of an inconsistency between the beliefs expressed by teachers and what they do in class. To address this, it is necessary to determine the factors that make teachers modify their practice against their beliefs and the time it takes for them to be "consumed by the system". This is an important issue for future research.

In the last area of beliefs related to mathematical abilities, the participants' positions were against statements suggesting that gender or culture make a difference in learning skills. However, there was a lower level of disagreement with the statements about mathematical skills being fixed and a natural talent. This phenomenon is also observed in the international study, where the belief in mathematical skills as a natural talent obtained the highest average score (around 3.5), even in the group of countries that have an incrementalview-endorsement, such as Germany, Switzerland, Chile, Taiwan, and Singapore [18]. Attention should be paid to this result because it could incentivize supporting students who are good at math but neglecting those who do not appear to have the skills.

Overall, the beliefs of both pre-service teachers and teacher educators were quite homogeneous between universities. In other words, the evidence from this study suggests that universities, as institutions, do not influence the beliefs of teacher educators. Similarly, the results do not show a significant association between TEPs, or the teacher educators who are part of each program, and the beliefs of pre-service teachers. This fact is supported 
by Tatto et al. [10], who claims that "there is little conclusive evidence that beliefs can be effectively influenced by teacher preparation" (p. 153).

Nevertheless, this should not discourage the efforts to know, shape, and change the beliefs of pre-service teachers during their training process. Identifying the beliefs that pre-service teachers have from their school experience with the teaching and learning of mathematics is essential to create strategies that redirect them, if necessary, and avoid them promoting negative attitudes towards mathematics in students. Many actions can be taken in TEPs to promote the desired constructivist orientations, for this, the existing positive and negative beliefs must be made visible, and the less pronounced positive beliefs must be cultivated [7].

\subsection{Variables Associated with Participant Beliefs}

The second research question aimed to identify correlations between the beliefs of pre-service teachers and other variables. We found that respondents who achieved better academic results in high school agree less with the idea that math skills are fixed. This result could be explained by participants believing that if they managed to get good grades, everyone can. However, when we analyzed the performance of the participants in a test related to mathematical knowledge for teaching, the data of the subjects from two universities showed the opposite behavior, it means. This suggests that their beliefs when they think of themselves as teachers differ from their beliefs when they see themselves as students.

Furthermore, the results obtained from the exploration of the relationships between the performance of the pre-service teachers in the TEDS-M test on mathematical knowledge and the belief scales did not show the correlations presented in the findings of the TEDSM study [10]. Results in the literature suggest positive correlations between student performance and the belief that mathematics is a process of inquiry and that learning requires active participation. Negative relationships between student outcomes and views of mathematics as a set of rules and procedures, teacher guidance being required to learn mathematics, and mathematics as a fixed skill are also mentioned [10]. However, the results with the Costa Rican pre-service teachers only evidenced a negative correlation between the results of the mathematical knowledge test and the belief that mathematics is a set of rules and procedures. These data must be interpreted with caution because the sample size is small, and there is a lack of participants from the other four TEPs.

Finally, the third question addresses the association of the teacher educators' beliefs and variables such as the TEPs, their teaching experience and their academic background. Our results showed that training in mathematics education makes a difference in beliefs about the teaching and learning of mathematics.

\section{Conclusions}

This project represents the first investigation to address the beliefs of pre-service mathematics teachers in Costa Rica, as well as those of their educators. Several studies have been carried out, but only with teachers in service. In this research, we found that our participants hold the belief that the nature of mathematics is dynamic, and its learning must follow a constructivist orientation. That profile is associated with the principles defined in the math curriculum of the Costa Rican Ministry of Education [1], which in turn are associated with better student results and strategies of teaching [7].

At first, this seems an encouraging result. However, there appears to be a phenomenon that does not allow novice teachers' practice to be consistent with their beliefs. This may be associated with the complex characteristics of the classroom context. This situation must be considered by education policymakers in order to provide school environments that are conducive to student-centered education, where learning can be built through discovery and investigation. This requires a manageable number of students, the necessary resources, and teachers being able to have agency in their actions. Moreover, Universities should concentrate on providing tools to pre-service mathematics teachers that allow them 
to overcome the factors that induce them to fall into traditional teaching methodologies, which, according to our results, do not coincide with their beliefs.

Notwithstanding the relatively limited sample, the knowledge offered by this work allows us to create an image of how the beliefs of our population are oriented. In addition to the size of the sample, there is an absence of participants from private universities. It would be valuable to complement our result with the information of the beliefs of the teachers in the training of these universities, since it is known that the programs differ in duration and contents studied, with respect to the TEPs of public universities [35].

Further research should be undertaken to investigate what happens to the beliefs of pre-service teachers in the transition from their TEPs to the classroom. It would also be interesting to perform a longitudinal study to analyze whether, how, and by which factors pre-service teachers' beliefs are modified during their TEPs. In doing so, the professed beliefs and those demonstrated in practice must be considered. This information will provide insights about which practices help to shape one or the other belief orientation.

Author Contributions: Conceptualization, H.A.V. and J.J.; methodology, H.A.V.; formal analysis, H.A.V.; investigation, H.A.V.; resources, H.A.V.; data curation, H.A.V.; writing-original draft preparation, H.A.V.; writing - review and editing, H.A.V. and J.J.; visualization, H.A.V.; funding acquisition, H.A.V. and J.J. All authors have read and agreed to the published version of the manuscript.

Funding: This research was funded by the University of Costa Rica, through the postgraduate study grant for the first author OAICE-CAB-160-2016. The APC was funded by Tampere University.

Institutional Review Board Statement: Not applicable.

Informed Consent Statement: Not applicable.

Data Availability Statement: The data are not publicly available due to privacy restrictions.

Acknowledgments: We would like to thank all the institutions and individuals that agreed to collaborate in this study.

Conflicts of Interest: The authors declare no conflict of interest.

\section{References}

1. Ministerio de Educación Pública. Programas de Estudio: Matemáticas. Available online: https://www.mep.go.cr/programaestudio/matematicas (accessed on 29 December 2020).

2. Programa Estado de la Nación. Resumen Séptimo Informe Estado de la Educación; Masterlitto: San José, Costa Rica, 2019.

3. Nespor, J. The role of beliefs in the practice of teaching. J. Curric. Stud. 1987, 19, 317-328. [CrossRef]

4. Pajares, M.F. Teachers' beliefs and educational research: Cleaning up a messy construct. Rev. Educ. Res. 1992, 62, 307-332. [CrossRef]

5. Speer, N. Issues of methods and theory in the study of mathematics teachers' professed and attributed beliefs. Educ. Stud. Math. 2005, 58, 361-391. [CrossRef]

6. Boz, N. Turkish pre-service mathematics teachers' beliefs about mathematics teaching. Aust. J. Teach. Educ. 2008, 33, 66-80. [CrossRef]

7. Voss, T.; Kleickmann, T.; Kunter, M.; Hachfeld, A. Mathematics teachers' beliefs. In Cognitive Activation in the Mathematics Classroom and Professional Competence of Teachers. Mathematics Teacher Education; Kunter, M., Baumert, J., Blum, W., Klusmann, U., Krauss, S., Neubrand, M., Eds.; Springer: Boston, MA, USA, 2013; Volume 8, pp. 249-271. [CrossRef]

8. Barkatsas, A.T.; Malone, J.A. Typology of mathematics teachers' beliefs about teaching and learning mathematics and instructional practices. Math. Educ. Res. J. 2005, 17, 69-90. [CrossRef]

9. Tang, S.J.; Hsieh, F.J. The cultural notion of teacher education: Future lower secondary teachers' beliefs on the nature of mathematics, the learning of mathematics and mathematics achievement. In International Perspectives on Teacher Knowledge, Beliefs and Opportunities to Learn; Blömeke, S., Hsieh, F.J., Kaiser, G., Schmidt, W., Eds.; Springer: Dordrecht, The Netherlands, 2014; pp. 231-253. [CrossRef]

10. Tatto, M.T.; Peck, R.; Schwille, J.; Bankov, K.; Senk, S.L.; Rodriguez, M.; Ingvarson, L.; Reckase, M.; Rowley, G. Policy, Practice, and Readiness to Teach Primary and Secondary Mathematics in 17 Countries: Findings from the IEA Teacher Education and Development Study in Mathematics (TEDS-M); International Association for the Evaluation of Educational Achievement: Amsterdam, The Netherlands, 2012.

11. Peterson, P.L.; Fennema, E.; Carpenter, T.P.; Loef, M. Teachers' pedagogical content beliefs in mathematics. Cogn. Instr. 1989, 6, 1-40. [CrossRef] 
12. Staub, F.C.; Stern, E. The nature of teachers' pedagogical content beliefs matters for students' achievement gains: Quasiexperimental evidence from elementary mathematics. J. Educ. Psychol. 2002, 94, 344-355. [CrossRef]

13. Stipek, D.J.; Givvin, K.B.; Salmon, J.M.; MacGyvers, V.L. Teachers' beliefs and practices related to mathematics instruction. Teach. Teach. Educ. 2001, 17, 213-226. [CrossRef]

14. Thompson, A.G. The relationship of teachers' conceptions of mathematics and mathematics teaching to instructional practice. Educ. Stud. Math. 1984, 15, 105-127. [CrossRef]

15. Raymond, A.M. Inconsistency between a beginning elementary school teacher's mathematics beliefs and teaching practice. J. Res. Math. Educ. 1997, 28, 550-576. [CrossRef]

16. Gamboa Araya, R.; Moreira Mora, T.E. Actitudes y creencias hacia las matemáticas: Un estudio comparativo entre estudiantes y profesores. Actual. Investig. Educ. 2017, 17, 514-559. [CrossRef]

17. Mora, F.; Campos, H. Qué es matemática? Creencias y concepciones en la enseñanza media costarricense. Cuad. Investig. Form. Educ. Mat. 2008, 4, 71-81.

18. Wang, T.Y.; Hsieh, F.J. The cultural notion of teacher education: Comparison of lower-secondary future teachers' and teacher educators' beliefs. In International Perspectives on Teacher Knowledge, Beliefs and Opportunities to Learn; Blömeke, S., Hsieh, F.J., Kaiser, G., Schmidt, W., Eds.; Springer: Dordrecht, The Netherlands, 2014; pp. 255-277. [CrossRef]

19. Thompson, A.G. Teachers' beliefs and conceptions: A synthesis of the research. In Handbook of Research in Mathematics Teaching and Learning; Grouws, D., Ed.; MacMillan: New York, NY, USA, 1992; pp. 127-146.

20. Furinghetti, F.; Pehkonen, E. Rethinking characterizations of beliefs. In Beliefs: A Hidden Variable in Mathematics Education? Pehkonen, E., Törner, G., Leder, G.C., Eds.; Springer: Dordrecht, The Netherlands, 2002; Volume 31, pp. 39-57.

21. Skott, J.; Mosvold, R.; Sakonidis, C. Classroom practice and teachers' knowledge, beliefs, and identity. In Developing Research in Mathematics Education: Twenty Years of Communications, Cooperation, and Collaboration in Europe; Dreyfus, T., Artigue, M., Potari, D., Prediger, S., Ruthven, K., Eds.; Routledge: Oxon, UK, 2018; pp. 162-180.

22. Sigel, I. A conceptual analysis of beliefs. In Parental Belief Systems: The Psychological Consequences for Children; Sigel, I.A., Ed.; Lawrence Erlbaum: Hillsdale, NJ, USA, 1985; Volume 1, pp. 345-371.

23. Richardson, V. The role of attitudes and beliefs in learning to teach. In Handbook of Research on Teacher Education; Sikula, J., Ed.; MacMillan: New York, NY, USA, 1996; pp. 102-119.

24. Schoenfeld, A.H. Learning to think mathematically: Problem solving, metacognition, and sense making in mathematics. In Handbook of Research on Mathematics Learning and Teaching; Grouws, D.A., Ed.; Macmillan: New York, NY, USA, 1992 ; pp. 334-370.

25. Philipp, R.A. Mathematics teachers' beliefs and affect. In Second Handbook of Research on Mathematics Teaching and Learning; Lester, F.K., Jr., Ed.; Information Age: Charlotte, NC, USA, 2007; pp. 257-315.

26. Felbrich, A.; Kaiser, G.; Schmotz, C. The cultural dimension of beliefs: An investigation of future primary teachers' epistemological beliefs concerning the nature of mathematics in 15 countries. ZDM Math. Educ. 2012, 44, 355-366. [CrossRef]

27. Ponte, J.P. Teachers' beliefs and conceptions as a fundamental topic in teacher education. In On Research in Teacher Education: From a Study of Teaching Practices to Issues in Teacher Education. Proceedings of the First Conference of the European Society for Research in Mathematics Education, Osnabrück, Germany, 27-30 August 1998; Krainer, K., Goffree, F., Berger, P., Eds.; Forschungsintitut für Mathematikdidaktik: Osnabrück, Germany, 1999; Volume 3, pp. 43-50.

28. McLeod, D.B. Research on affect in mathematics education: A reconceptualization. In Handbook of Research on Mathematics Learning and Teaching; Grouws, D.A., Ed.; Macmillan: New York, NY, USA, 1992; pp. 575-596.

29. Op't Eynde, P.; De Corte, E.; Verschaffel, L. Framing students' mathematics-related beliefs. In Beliefs: A Hidden Variable in Mathematics Education? Pehkonen, E., Törner, G., Leder, G.C., Eds.; Springer: Dordrecht, The Netherlands, 2002; Volume 31, pp. 13-37.

30. Blömeke, S.; Kaiser, G. Theoretical framework, study design and main results of TEDS-M. In International Perspectives on Teacher Knowledge, Beliefs and Opportunities to Learn; Blömeke, S., Hsieh, F.J., Kaiser, G., Schmidt, W., Eds.; Springer: Dordrecht, The Netherlands, 2014; pp. 19-47. [CrossRef]

31. Grigutsch, S.; Raatz, U.; Törner, G. Einstellungen gegenüber Mathematik bei Mathematiklehrern. J. Math-Didakt. 1998, 19, 3-45 [CrossRef]

32. Alfaro, H.; Joutsenlahti, J. What skills and knowledge do university mathematics teacher education programs give future teachers in Costa Rica? Eur. J. Sci. Math. Educ. 2020, 8, 145-162.

33. Tatto, M.T.; Schwille, J.; Senk, S.; Ingvarson, L.; Peck, R.; Rowley, G. Teacher Education and Development Study in Mathematics (TEDS-M): Policy, Practice, and Readiness to Teach Primary and Secondary Mathematics. Conceptual Framework; Teacher Education and Development International Study Center, College of Education, Michigan State University: East Lansing, MI, USA, 2008.

34. Peker, M.; Ulu, M. The effect of pre-service mathematics teachers' beliefs about mathematics teaching-learning on their mathematics teaching anxiety. Int. J. Instr. 2018, 11, 249-264. [CrossRef]

35. Alfaro, A.L.; Alpízar, M.; Morales, Y.; Ramírez, M.; Salas, O. La formación inicial y continua de docentes de matemáticas en Costa Rica. Cuad. Investig. Form. Educ. Mat. 2013, 8, 131-179. 